\title{
Cross-sectional echocardiographic findings of anomalous origin of left coronary artery from pulmonary artery
}

\author{
MASARU TERAI, YOKO NAGAI, TSUYOSHI TOBA \\ From Department of Paediatrics, Chiba Municipal Hospital, Chiba-shi, fapan
}

SUMMARY Anomalous origin of the left coronary artery and left ventricular myocardial hypokinesis were visualised by cross-sectional echocardiography. Significant dilatation of the right coronary artery was another important finding. Cross-sectional echocardiography appears to be useful for evaluating patients with anomalous origin of the left coronary artery from the pulmonary artery.

Anomalous origin of the left coronary artery from the pulmonary artery is a rare congenital cardiac anomaly. ${ }^{1}$ Because the majority of patients with this lesion die in infancy, ${ }^{1-3}$ its early recognition and proper treatment are essential. In this report we describe a 4 month old girl with this lesion, in whom cross-sectional echocardiography was useful for early diagnosis, and we discuss the cross-sectional echocardiographic findings.

\section{Case report}

A $3355 \mathrm{~g}$ baby girl was born after a spontaneous vaginal delivery and an uncomplicated pregnancy. Her growth and development appeared normal until 3 months of age when poor feeding, crying spells, and tachypnoea were noticed. When admitted at 4 months of age, she was underdeveloped and dyspnoeic, with grunting. The heart sounds were distant and there were no murmurs. The liver was palpable $4 \mathrm{~cm}$ below the right costal margin. The chest $x$-ray film showed gross cardiomegaly. The electrocardiogram showed anterolateral infarction. The $M$-mode echocardiogram showed an enlarged left ventricle, and the ejection fraction of the left ventricle was much reduced to $15 \%$.

The cross-sectional echocardiographic study using an Aloka SSD-110S mechanical sector scanner with a $3 \mathrm{MHz}$ transducer showed similar findings. In addition, on the cross-section through the aortic root and pulmonary artery, the dilated right coronary artery with normal origin and the left coronary artery originating from the posterior wall of the pulmonary artery could be visualised (Fig.). In addition, we could clearly identify its bifurcation into anterior descending and circumflex branches. At the age of 6 months, cardiac catheterisation showed a minimal step-up of oxygen saturation in the pulmonary artery. The retrograde aortogram showed a dilated right coronary artery and a retrograde flow through the left coronary artery into the pulmonary artery, which confirmed the diagnosis.

\section{Discussion}

Cross-sectional echocardiography has been validated as a non-invasive reliable way of making a diagnosis in a critically ill infant with various congenital heart diseases. As far as we know there has been only a limited number of reports, however, on the cross-sectional echocardiographic findings of anomalous origin of the left coronary artery from the pulmonary artery. Caldwell et al. ${ }^{4}$ reported three patients who had characteristic segmental asynergy of the left ventricle, but the left coronary artery was not directly shown. Subsequently, Fisher et al..$^{5}$ reported two patients whose diagnosis was confirmed angiographically, and they were able to visualise the left coronary artery on cross-sectional echocardiogram directly. In our case, also, we could visualise the anomalous origin of the left coronary artery from the pulmonary artery directly on cross-sectional echocardiography, and this was useful for evaluation before catheterisation. The short axis view through the aortic root and the pulmonary valve was the plane chosen to show the anomalous origin of the left coronary artery and its 

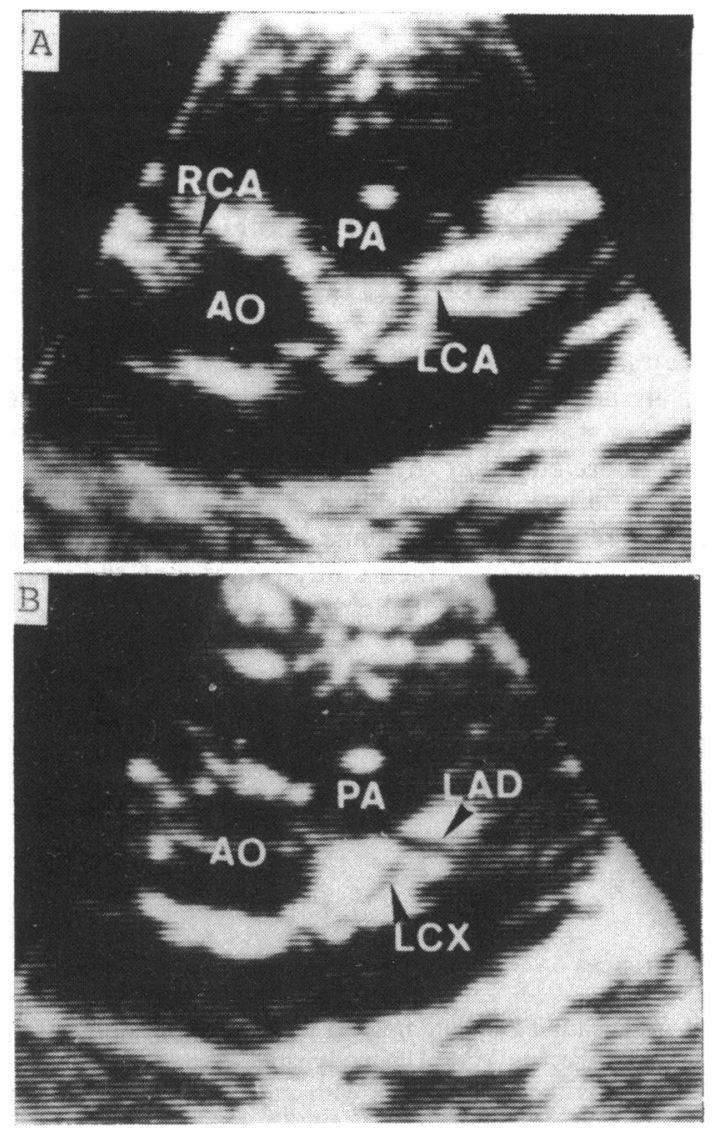

Fig. Short axis cross-sectional echocardiograms through the aortic root and pulmonary valve. (A) The dilated right coronary artery $(R C A)$ with normal origin and the left coronary artery (LCA) originating from the pulmonary artery $(P A)$ are seen. $A O$, aorta. (B) The left coronary artery bifurcates into the left anterior descending artery $(L A D)$ and the left circumflex artery (LCX).

course. Significant dilatation of the right coronary artery was another important finding. If only a dilated right coronary artery can be seen in a patient who is suspected of having anomalous origin of the left coronary artery from the pulmonary artery, a very careful examination around the pulmonary artery should be performed.

In most infants with this lesion who have symptoms, intercoronary collateral networks are underdeveloped. This leads to myocardial ischaemia and frequently infarction, which often produces clinical mitral regurgitation caused by papillary muscle dysfunction. If these infants survive the initial critical period, multiple collateral channels between the right coronary artery and the anomalous left coronary artery will develop, and this may result in the potential for a "steal" phenomenon. That may again lead to further myocardial ischaemia. None the less, patients with this lesion almost invariably have extensive myocardial scarring or so-called ischaemic cardiomyopathy which often causes a significant degree of left ventricular wall motion abnormality. 46 The severity of left ventricular myocardial hypokinesis and the degree of left ventricular dilatation are very important factors in prognosis, ${ }^{7}$ and therefore preoperative accurate assessment of left ventricular function and wall motion is essential for patients with this lesion. For this purpose, cross-sectional echocardiography can be used very effectively, though a few minor problems remain in the quantification of asynergy.

\section{References}

1 Keith JD, Rowe RD, Vlad P. Heart disease in infancy and childhood. 3rd ed. New York: Macmillan, 1978: 1014-9.

2 Wesselhoeft H, Fawcett JS, Johnson AL. Anomalous origin of the left coronary artery from the pulmonary trunk. Its clinical spectrum, pathology, and pathophysiology, based on a review of 140 cases with seven further cases. Circulation 1968; 38: 403-25.

3 Perry LW, Scott LP. Anomalous left coronary artery from pulmonary artery: report of 11 cases; review of indications for and results of surgery. Circulation 1970; 41: 1043-52.

4 Caldwell RL, Weyman AE, Girod DA, Hurwitz RA, Feigenbaum H. Cross-sectional echocardiographic differentiation of anomalous left coronary artery from primary myocardopathy [Abstract]. Circulation 1978; 58: 11-202.

5 Fisher EA, Sepehri B, Lendrum B, Luken J, Levitsky S. Two-dimensional echocardiographic visualisation of the left coronary artery in anomalous origin of the left coronary artery from the pulmonary artery. Pre- and postoperative studies. Circulation 1981; 63: 698-704.

6 Wasserman LA, Eshaghpour E, Takahashi O, Iskandrian A, Kloter MN. The noninvasive assessment of anomalous origin of the left coronary artery from the pulmonary artery. Cathet Cardiovasc Diagn 1979; 5: 8593.

7 Driscoll DJ, Nihill MR, Mullins CE, Cooley DA, McNamara DG. Management of symptomatic infants with anomalous origin of the left coronary artery from the pulmonary artery. Am $\mathcal{F}$ Cardiol 1981; 47: 642-8.

Requests for reprints to Dr Masaru Terai, Department of Paediatrics, Chiba Municipal Hospital, 827 Yahagi-cho, Chiba-shi, 280 Japan. 